\title{
Disordered eating and menstrual patterns in female university netball players
}

\author{
Lize Havemann (PhD Exercise Science) \\ Zelda De Lange (MSc Nutrition) \\ Karen Pieterse (BSc Hons Nutrition) \\ Hattie H Wright (PhD Nutrition)
}

Centre of Excellence for Nutrition (CEN), North-West University, Potchefstroom, South Africa

Correspondence to: L Havemann-Nel (Lize.HavemannNel@nwu.ac.za)

\begin{abstract}
Objective. The primary aim of this study was to determine the prevalence of disordered eating (DE) behaviour and menstrual disorders in a group of provincial-to-national level student netball players. The secondary aim was to examine the relationship between body composition, energy intake, DE and menstrual patterns in student netball players.

Methods. Twenty-six white female netball players from a South African university volunteered to participate in this cross-sectional descriptive study. Height, weight and body composition were measured. Energy intake was assessed with 24-hour recalls and menstrual patterns were assessed with a menstrual history questionnaire. Players also completed an Eating Disorder Inventory (EDI) and an Eating Attitudes Test (EAT-26) to assess DE behaviour.

Results. Collectively 14 players $(54 \%)$ were identified with DE behaviour and scored above the designated cut-off score for the EAT-26 $(\geq 20, N=3)$, the EDI Body Dissatisfaction subscale $(\geq 14$, $N=7$ ), the EDI Drive for Thinness subscale ( $\geq 15, N=3$ ), and/or answered 'Yes' $(N=8)$ to $D E$ behavioural questions. Eight players $(31 \%)$ reported menstrual irregularities during the past 12 months, of whom four (15\%) also reported secondary amenorrhoea (absence of $\geq 3$ consecutive menstrual cycles) during training. Five players $(19 \%)$ presented with DE behaviour, menstrual irregularity and primary and/or secondary amenorrhoea. Reported energy intake was significantly lower in the players with menstrual irregularities and secondary amenorrhoea compared with the remaining players $(p<0.05)$.

Conclusions. Top female student netball players may have suboptimal energy intakes and suffer from DE behaviour, menstrual irregularities and secondary amenorrhoea. Players and coaches should be aware of these risks to avoid related health and performance consequences.
\end{abstract}

\section{Introduction}

Women's participation in sports has increased substantially over the past few years, and this growth, especially on a competitive level, has been accompanied by a number of health concerns including disordered eating (DE) and menstrual disorders. ${ }^{1,2}$ Apart from the societal pressure on women to be beautiful and thin, many female athletes are also pressured by coaches or the type of sport they are competing in (i.e. lean-build sports) to maintain a low body weight for aesthetic and/or performance purposes. This often contributes towards the development of DE and pathogenic bodyweight-control behaviours (i.e. restrictive eating, fasting, use of diet pills, laxatives and diuretics, binge-eating followed by purging) that can result in clinical eating disorders (i.e. anorexia nervosa and bulimia nervosa) and alterations in menstrual patterns. ${ }^{1}$ Potential long-term health consequences of DE and menstrual disorders include chronic fatigue, anaemia, endocrine abnormalities, and osteoporosis, to name a few. ${ }^{1,2}$ Female student athletes may be at an even higher risk for DE owing to the added pressure of maintaining an attractive and culturally acceptable body shape, and adapting to the new social and academic environment of a tertiary educational institution (e.g. college or university).

Reported prevalence of DE and menstrual disorders in female university athletes varies and depends on a number of factors, including type of sport, level of participation, and type of questionnaire used to screen for $\mathrm{DE} .^{1-3}$ Although a number of studies have reported a higher prevalence of DE and menstrual disorders in female university athletes compared with non-athletes, particularly in elite female athletes competing in aesthetic, weightclass and endurance sports where leanness is emphasised, ${ }^{4,5}$ other studies failed to demonstrate differences in the frequency of $D E$ and menstrual disorders between athletes and non-athletes, especially in sports where leanness is considered less important. ${ }^{2,3}$ The primary aim of this study was therefore to determine the prevalence of DE behaviour and menstrual disorders in a group of provincial-tonational level student netball players.

\section{Methodology}

\section{Subjects and study design}

Twenty-six white female netball players from a South African university volunteered to take part in this descriptive, cross-sectional study which was approved by the Ethics Committee of the North-West University. Students representing the University's 1st, 2nd or U/19A netball teams were invited to participate in the study. The majority of these players also represented a provincial and/or national netball team in the past three years. The characteristics of the subjects are summarised in Table I. The subjects were informed of the nature of the study and written informed consent was obtained prior to the start of the study. Pregnancy or known gynaecological problems were exclusion criteria. Oral contraceptive use was not an exclusion criterion but the reason for use, i.e. to regulate menstrual cycle, was documented. 
TABLE I. Subject characteristics ( $N=26)$

\begin{tabular}{lll}
\hline Characteristic & Mean $( \pm \mathrm{SD})$ & Range \\
\hline Age $($ years $)$ & $19 \pm 1$ & $18-22$ \\
Weight $(\mathrm{kg})$ & $70.8 \pm 10.8$ & $55.0-91.8$ \\
Height $(\mathrm{m})$ & $1.75 \pm 0.06$ & $1.56-1.84$ \\
Body mass index $\left(\mathrm{kg} / \mathrm{m}^{2}\right)$ & $23.2 \pm 2.8$ & $19.4-28.7$ \\
Body fat percentage & $25.2 \pm 4.8$ & $14.6-36.5$ \\
Energy intake $(\mathrm{MJ})$ & $8.7 \pm 2.4$ & $4.4-14.6$ \\
Training volume (sessions/week) & $5 \pm 1$ & $3-6$ \\
Training volume (sessions/day) & $1.7 \pm 0.6$ & $1-3$ \\
& & \\
SD = standard deviation. & & \\
\end{tabular}

For the purpose of the study, subjects were required to report to the laboratory for the assessment of height, weight and body composition. In addition, subjects were required to complete the following questionnaires: (i) a demographic and sport questionnaire for the attainment of socio-demographic information and training volume; (ii) three 24-hour dietary recalls for the estimation of mean reported energy intake; (iii) a menstrual history questionnaire to assess menstrual patterns; and (iv) an Eating Disorder Inventory (EDI) and an Eating Attitude Test (EAT-26) to assess risk for disordered eating.

\section{Weight, height and body composition}

Weight and height were recorded to the nearest decimal position with an electronic Precision Health scale (Model UC-300, A\&D Company Ltd., Tokyo, Japan) and an Invicta stadiometer (Model IP 1465, Invicta, London, UK), respectively. Body composition (fatfree mass, fat mass and body fat percentage) was determined with air-displacement plethysmography (ADP) using the BODPOD body compositions system (Model 2000A, COSMED USA, Inc., Concord, CA, USA) as described by McCrory et al. ${ }^{8}$

\section{Dietary and energy intake}

Dietary and energy intake were recorded with a 24-hour dietary recall on three non-consecutive days. All dietary data were analysed with the Foodfinder ${ }^{\mathrm{TM}} 3$ software program (Version 1.1.3, 2002, Medical Research Council, SA) and expressed in kilocalories. The possibility of under-reporting of energy intake in the present study was evaluated by the calculation of the mean reported energy intake (Ei) in relation to calculated basal metabolic rate (BMR) (Ei:BMR) according to the method of Goldberg. ${ }^{9}$ The Ei:BMR was adjusted for females with different physical activity levels (PAL) as described by Black $^{10}$ and values $<1.11$ (cut-off for females with a medium PAL) were considered as possible under-reporting. ${ }^{10}$

\section{Disordered eating}

DE behaviour was assessed with the EAT-26 questionnaire ${ }^{6}$ and the EDI. ${ }^{7}$ The validity and reliability of both questionnaires have been described previously. 6,7

\section{The EAT-26}

The EAT-26 is a standardised questionnaire designed to identify eating disorder risk and DE behaviour in high school, university and other special risk samples such as athletes. The instrument consists of 26 items rated on a 6-point Likert-type scale together with four eating behaviour questions which require a 'Yes' or 'No' response.
Respondents with a total EAT-26 score of 20 or higher and/or who answered 'Yes' to any of the behavioural questions were classified with DE behaviour.

\section{EDI}

The EDI is a self-reported measure designed to assess attitudes, feelings and behaviours typically associated with eating disorders (EDs), and has been found to be a suitable screening instrument for EDs in a non-clinical setting. ${ }^{7}$ The EDI consists of 64 items rated on a 6-point Likert-type scale, and is subdivided into eight subscales. ${ }^{7}$ Total EDI score and independent subscale scores were used to make comparisons between players with menstrual irregularities and those without. The EDI Drive for Thinness (EDI-DT) and Body Dissatisfaction (EDI-BD) subscales have been shown to predict the development of EDs and have been used as selection criteria when investigating the prevalence of EDs in elite athletes, ${ }^{11}$ and will therefore also be used to identify players with ED risk and DE behaviour in the present study. Respondents scoring $\geq 15$ in the EDI-DT and/or $\geq 14$ in the EDI-BD subscale were considered to be 'at risk' for EDs. ${ }^{11}$

\section{Menstrual patterns}

Menstrual patterns were assessed with a menstrual history questionnaire that included questions regarding age of menarche, frequency and regularity of menstrual cycles, training-associated changes in cycle frequency and regularity, and oral contraceptive use. For the purpose of this study menstrual dysfunction included a history of secondary amenorrhoea (defined as the absence of three or more consecutive menstrual periods at any time since menarche) and/or primary amenorrhoea (defined as the absence of menstruation by age 15). ${ }^{12}$ Menstrual irregularity was defined as one or more of the following: (i) cycles not occurring every 28 - 34 days; (ii) fewer than 10 cycles in the past 12 months; and/or (iii) fewer than 5 cycles in the past 6 months.

\section{Statistical analysis}

Data were analysed using STATISTICA analysis software (Version 10, Statsoft, Tulsa, OK, USA). Normally distributed descriptive data were reported as means \pm standard deviations (SD) and non-parametric data were reported as medians and inter-quartiles ranges. Spearman rank correlations were used to explore associations between energy intake, training volume, body composition and DE (EAT-26, total EDI and EDI subscale scores), and non-parametric Mann-Whitney $U$-tests were performed to test differences between groups with different menstrual patterns and DE behaviour.

\section{Results \\ Energy intake and training volume}

Total mean reported energy intake and training volume are summarised in Table I. Mean reported energy intake in relation to calculated basal metabolic rate (Ei:BMR) was $1.33 \pm 0.37$. Six players $(23 \%)$ had an Ei:BMR value of $<1.11$ (1.05, 0.90, 0.63, 0.91, 0.95, and 0.90, respectively) which would normally be considered under-reporting. ${ }^{10}$ However, since low energy intakes among female athletes are not uncommon, ${ }^{2}$ possible under-reporting was noted but not excluded from the analysis. Furthermore, the under-reporting data did not significantly lower mean reported energy intake $(8.7 \pm 2.4$ v. $9.5 \pm 2.1$ $\mathrm{MJ}, p=0.19)$ and three of the under-reporters were identified with $\mathrm{DE}$ behaviour.

\section{Disordered eating}

Total EAT-26 scores of the group of female netball players $(N=26)$ are summarised in Fig. 1. Total mean EAT-26 score was $9.4 \pm 6.9$, and 


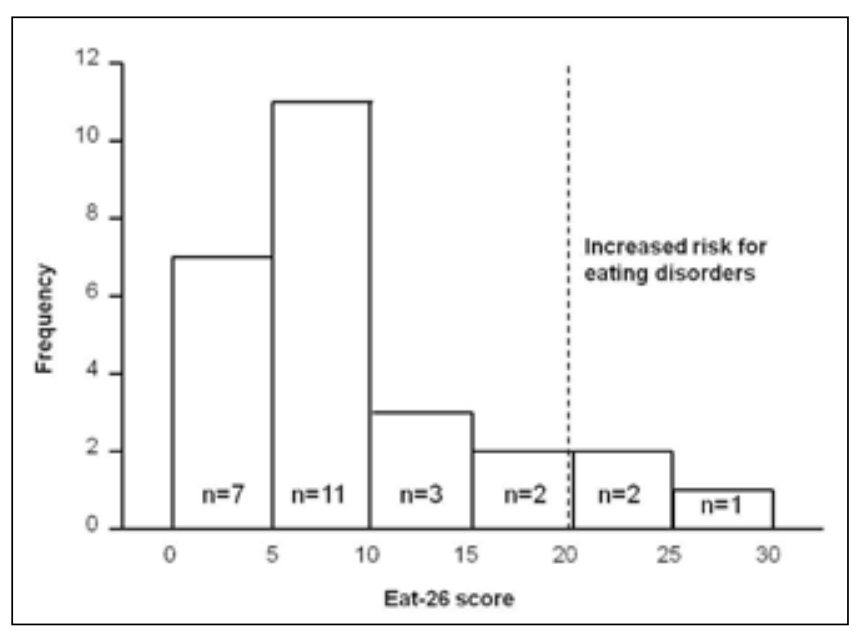

Fig. 1. Total EAT-26 scores.

10 players (38\%) responded 'Yes' to one or more of the behavioural questions and/or scored above the designated cut-off score $(\geq 20)$ in the EAT-26. Four of the 10 subjects also scored $\geq 15$ in the EDIDT and/or $\geq 14$ in the EDI-BD. Total mean EDI-BD and EDI-DT subscale scores were $9.5 \pm 5.8$ and $5.5 \pm 5.3$, respectively. Seven subjects $(27 \%)$ scored $\geq 14$ in the EDI-BD and three subjects (12\%) scored $\geq 15$ in the EDI-DT. Collectively 14 players (54\%) scored above the designated cut-off scores for either/or the EAT-26, EDI-BD, EDI-DT, and/or answered 'Yes' to one or more of the EAT-26 behavioural questions, identifying them with $D E$ behaviour and an increased ED risk. No significant differences were demonstrated for weight, training volume or energy intake when the group with $D E$ behaviour $(N=14)$ was compared with the group without $D E$ behaviour $(N=12)$.

There was no association between reported energy intake, training volume, body composition, total EAT-26 score or total EDI score in this group of female netball players. A weak, but positive

TABLE II. Menstrual patterns and oral contraceptive use $(\mathbf{N}=26)$

\begin{tabular}{|c|c|}
\hline Regularity of menstrual cycles & $N(\%)$ \\
\hline $\begin{array}{l}\text { Regular (every } 28-34 \text { days } / 10-12 \text { cycles during past } \\
12 \text { months) }\end{array}$ & $18(69 \%)$ \\
\hline $\begin{array}{l}\text { Irregular (not every } 28-34 \text { days } /<10 \text { cycles during past } \\
12 \text { months } /<5 \text { cycles during past } 6 \text { months) }\end{array}$ & $18(31 \%)$ \\
\hline \multicolumn{2}{|l|}{ History of menstrual dysfunction } \\
\hline Primary amenorrhoea & $1(3.8 \%)$ \\
\hline Secondary amenorrhoea & $5(19 \%)$ \\
\hline \multicolumn{2}{|l|}{ Changes in cycle during athletic season } \\
\hline Yes & $15(58 \%)$ \\
\hline No & $11(42 \%)$ \\
\hline \multicolumn{2}{|l|}{ Type of changes in response to training } \\
\hline Shorter cycle & $6(23 \%)$ \\
\hline Increased length of cycle & $5(19 \%)$ \\
\hline $\begin{array}{l}\text { Absence of } 3 \leq \text { consecutive cycles (secondary-training } \\
\text { amenorrhoea) }\end{array}$ & $4(15 \%)$ \\
\hline \multicolumn{2}{|l|}{ Oral contraceptive use } \\
\hline Total oral contraceptive use & $4(15 \%)$ \\
\hline Oral contraceptive use to 'regulate menstrual cycle' & $3(12 \%)$ \\
\hline Oral contraceptive use to 'treat skin problems' & $1(3.8 \%)$ \\
\hline
\end{tabular}

correlation was reported between energy intake and EDI-BD subscale score $(r=0.39, p<0.05)$. Training volume (sessions/week) was negatively correlated with EDI-DT and perfectionism subscale scores $(r=-0.42$ and $r=-0.46$ respectively, $p<0.05)$.

\section{Menstrual patterns}

Reported menstrual patterns, including menstrual regularity, history of menstrual dysfunction, changes in menstrual cycle in response to the athletic season and oral contraceptive use are summarised in Table II. Eight of the subjects (31\%) reported irregular menstrual cycles during the past 12 months, of whom 6 players (23\%) also reported a history of menstrual dysfunction, e.g. the absence of menstruation by age 15 (primary amenorrhoea) and/or the absence of three or more consecutive menstrual periods at any time since menarche (secondary amenorrhoea). Three of these players also reported the use of oral contraceptives with documented reason for use: 'to regulate irregular menstrual cycle'. Five of the players with irregular menstrual cycles and menstrual dysfunction were also identified with DE behaviour.

When comparing the group with irregular menstrual cycles $(N=8)$ with the group with regular menstrual cycles $(N=18)$ (Table III), reported energy intake was significantly lower in the irregular compared with the regular group $(p<0.001)$. In addition, total EAT-26, total EDI, and EDI-DT subscale scores, although not significantly, were higher in the group who reported irregular menstrual cycles.

\begin{tabular}{|c|c|c|c|}
\hline $\begin{array}{l}\text { Character- } \\
\text { istic }\end{array}$ & Irregular $(\mathrm{N}=8)$ & Regular (N=18) & $p$-level \\
\hline Weight (kg) & $65.1(62.6-74.7)$ & $69.1(63.0-78.5)$ & $p=0.567$ \\
\hline Height (m) & $1.74(1.70-1.79)$ & $1.75(1.70-1.81)$ & $p=0.461$ \\
\hline BMI $\left(\mathrm{kg} / \mathrm{m}^{2}\right)$ & $22.1(21.0-23.7)$ & $22.9(21.3-26.2)$ & $p=0.605$ \\
\hline $\begin{array}{l}\text { Body fat } \\
\text { percentage }\end{array}$ & $24.6(20.9-26.7)$ & $25.3(22.8-28.3)$ & $p=0.531$ \\
\hline $\begin{array}{l}\text { Energy intake } \\
\text { (MJ) }\end{array}$ & $6.4(5.9-7.4)$ & $9.2(8.2-11.4)$ & $p<0.001$ \\
\hline $\begin{array}{l}\text { Training } \\
\text { volume (ses- } \\
\text { sions/week) }\end{array}$ & $5.0(3.5-5.0)$ & $5.0(4.0-6.0)$ & $p=0.515$ \\
\hline $\begin{array}{l}\text { Total EAT-26 } \\
\text { score }\end{array}$ & $12.0(6.0-19.5)$ & $8.0(3.0-10.0)$ & $p=0.311$ \\
\hline $\begin{array}{l}\text { Total EDI } \\
\text { score }\end{array}$ & $37.0(23.5-56.5)$ & $26.0(22.0-36.0)$ & $p=0.285$ \\
\hline $\begin{array}{l}\text { EDI-BD sub- } \\
\text { scale score }\end{array}$ & $8.5(5.0-11.5)$ & $10.0(4.0-14.0)$ & $p=0.495$ \\
\hline $\begin{array}{l}\text { EDI-DT sub- } \\
\text { scale score }\end{array}$ & $10.0(2.5-13.5)$ & $3.0(2.0-5.0)$ & $p=0.144$ \\
\hline
\end{tabular}

The athletic season had the biggest impact on the menstrual patterns in this specific group of netball players, with the majority of subjects $(N=15,58 \%)$ reporting changes in menstrual cycle during the athletic season. Of note are the four subjects (15\%) who reported the absence of three or more consecutive menstrual periods during the athletic season (secondary-training amenorrhoea). Although the sample size of the group with secondary-training amenorrhoea was very small $(N=4)$, non-parametric Mann-Whitney $U$-tests were 
performed to examine possible differences between players with secondary-training amenorrhoea and those without. On analysis, the players with secondary-training amenorrhoea reported a significantly lower energy intake compared with the players without secondary-training amenorrhoea $(6.4(6.0$ - 7.0) v. $8.6(7.7-11.0)$ $\mathrm{MJ}, p<0.05)$. Although three of the four players were identified as possible under-reporters (Ei:BMR <1.11), these players were also identified with DE behaviour (scored above the designated cut-off in the EAT-26, EDI-BD and/or EDI-DT). The players with secondarytraining amenorrhoea also scored significantly higher in the EDI-DT and Perfectionism subscales (10.5 (7.0 - 13.5) v. $3.0(1.0-6.0)$, and $10.5(7.5-14.5)$ v. $4.0(2.0-8.0)$, respectively, $p<0.05)$ as well as in the EAT-26 Bulimia and Food Preoccupation subscale (3.0 (2.3 - 3.5) v. $2.0(1.0-2.0), p<0.05)$.

\section{Discussion}

The present study investigated DE behaviour and menstrual patterns in a group of provincial-to-national level student netball players enrolled at a South African university. Collectively 14 players $(54 \%)$ were identified with DE behaviour, eight players $(31 \%)$ reported menstrual irregularities during the past 12 months, of whom four $(15 \%)$ reported secondary amenorrhoea during training, and five (19\%) presented with DE behaviour and menstrual irregularity and dysfunction.

To our knowledge data on $\mathrm{DE}$ behaviour and menstrual patterns in female university netball players are scarce. The prevalence of $D E$ in female university athletes reported in the literature is inconsistent and can be attributed to differences in sampling and the use of different assessment instruments.1-3 The outcome on DE behaviour based on the EAT-26 (score $\geq 20$ ) in the group of university netball players in the present study $(12 \%)$ is comparable with those of Hoerr et al.., Kirk et al. ${ }^{14}$ and Beals and Manore ${ }^{15}$ who also applied the EAT-26 and reported a prevalence of $12 \%, 9.6 \%$ and $15 \%$, respectively in female university athletes/athletes aged $18-24$ years. Kirk et al. ${ }^{14}$ assessed a group of 94 NCAA Division 1 collegiate female athletes competing in a number of non-lean-build sports including soccer $(N=24,17 \%$ scored $\geq 20)$, tennis $(N=10,0 \%$ scored $\geq 20)$, softball $(N=18,5.6 \%$ scored $\geq 20)$, basketball $(N=11,0 \%$ scored $\geq 20)$ and lacrosse $(N=31$, $13 \%$ scored $\geq 20$ ). Beals and Manore ${ }^{15}$ used the EDI-BD subscale in conjunction with the EAT-26 to assess DE behaviour in a group of 96 collegiate female athletes competing in team/anaerobic sports including golf, softball, tennis, volleyball and field events. However, they applied a lower EDI-BD cut-off point than in the present study (12 v. 14), explaining the higher percentage of female athletes identified with 'elevated' EDI-BD scores $(42 \%$ v. $27 \%)$ compared with the present study. Similar to the present study, Torstveit et al. ${ }^{16}$ showed that $22 \%$ of 96 elite female athletes (mean age 23.5 years) competing in non-lean-build sports (including technical, ball game and power sports) scored $\geq 14$ on the EDI-BD. In addition, Torstveit et al. ${ }^{16}$ reported that $6.3 \%$ of athletes scored $\geq 15$ on the EDI EDI-DT subscale. Reinking and Alexander ${ }^{17}$ also reported a lower EDI-DT outcome $(2.9 \%)$ compared with the present study in a group of 68 females competing in non-lean-build sports. A smaller sample size, a higher mean BMI $\left(23.7 \pm 2.8 \mathrm{v} .22 .7 \pm 2.2 \mathrm{~kg} / \mathrm{m}^{2}\right)$ and a higher body weight $(70.8 \pm 10.8$ v. $66.8 \pm 8.3$ and $65.6 \pm 7.8 \mathrm{~kg})$ in the present study can possibly explain differences in EDI-DT outcomes.

Reported menstrual irregularity and menstrual dysfunction in the present study concur with the literature on menstrual patterns in collegiate females competing in non-lean-build sports. Beals and Manore $^{15}$ showed that $24 \%$ of 96 collegiate females competing in team/anaerobic sports reported menstrual irregularities and $4.3 \%$ reported primary amenorrhoea. Torstveit and Sundgot-Borgen ${ }^{18}$ reported that $21 \%$ of 302 elite female athletes competing in ball sports reported a history of menstrual dysfunction (delayed menarche and secondary amenorrhoea) and 13\% reported current secondary amenorrhoea. In another study from the same authors, ${ }^{19}$ $9.3 \%$ of female football players and $19 \%$ of female handball players reported current secondary amenorrhoea. Although Beals and Hill ${ }^{20}$ reported a much higher prevalence of menstrual irregularities (72\%) in a group of 47 female athletes competing in intercollegiate nonlean-build sports (tennis, field hockey and softball), they applied less strict criteria for identifying menstrual irregularity $(<12$ cycles in the past 12 months, $<6$ cycles in the past 6 months, $>10-d$ variation). The frequency of menstrual dysfunction (delayed menarche and secondary amenorrhoea), however, was comparable to the present study $(17 \%$ v. $19 \%){ }^{20}$

The disruption of normal menses with exercise training has long been recognised and is more common among athletes than non-athletes. ${ }^{5,11}$ A number of factors have been implicated in the development of menstrual disturbances and include $\mathrm{DE}$, low energy intake, and strenuous exercise training. ${ }^{1}$ Indeed, reported energy intake in the present study was significantly lower in the players who reported menstrual irregularities and secondarytraining amenorrhoea compared with those players without menstrual disorders. Furthermore, although not significant, players with menstrual irregularities reported higher EAT-26 and EDI scores compared with the regular group. In addition, subjects with secondary-training amenorrhoea scored significantly higher on the EDI-DT and Perfectionism subscales $(p<0.05)$ as well as the EAT-26 Bulimia and Food Preoccupation subscales $(p<0.05)$ compared with the players without secondary-training amenorrhoea.

It is difficult to explain the weak positive correlation between energy intake and EDI-BD as well as the inverse relationship between training volume and EDI-DT and Perfectionism subscale scores, as DE in athletes is generally associated with a lower energy intake and higher training volume. These correlations could possibly be the result of multiple testing. Other limitations in the present study that warrant mentioning include a small sample size and the fact that a control group of non-athletes was not included in the study.

In conclusion, reported menstrual irregularity, menstrual dysfunction and DE behaviour in the present study seem to be in line with the literature on prevalence of menstrual disorders and $D E$ in female student athletes participating in non-lean-build sports. The present study therefore highlights the fact that student netball players are also at risk for developing EDs, restricting energy intakes, and experiencing menstrual disorders. This is of practical significance to university netball players, parents, netball coaches and health professionals working with netball players to increase awareness, facilitate intervention and prevent the health and performance consequences associated with $D E$ behaviour and menstrual disorders.

\section{REFERENCES}

1. Nattiv $A$, Loucks $A B$, Manore $M M$, et al American College of Sports Medicine position stand. The female athlete triad. Med Sci Sports Exerc 2007;39(10):1867-1882.

2. Beals KA, Meyer NL. Female athlete triad update. Clin Sports Med 2007;26(1):69-89.

3. Coelho GM, Soares Ede A, Ribeiro BG. Are female athletes at increased risk for disordered eating and its complications? Appetite 2010;55(3):379387

4. Sundgot-Borgen J. Disordered eating and exercise. Scand J Med Sci Sports 2004:14(4):205-207.

5. Sundgot-Borgen J, Torstveit MK. Prevalence of eating disorders in elite athletes is higher than in the general population. Clin $\mathrm{J}$ Sport Med 2004;14(1):25-32. 
6. Garner DM, Olmsted MP, Bohr Y, Garfinkel PE. The eating attitudes test: psychometric features and clinical correlates. Psychol Med 1982;12(4):871878.

7. Garner DM, Olmstead MP, Polivy J. Development and validation of a multidimensional eating disorder inventory for anorexia nervosa and bulimia. Int J Eat Dis 1983;2(2):15-34.

8. McCrory MA, Gomez TD, Bernauer EM, Mole PA. Evaluation of a new air displacement plethysmograph for measuring human body composition. Med Sci Sports Exerc 1995;27(12):1686-1691.

9. Goldberg GR, Black AE, Jebb SA, et al. Critical evaluation of energy intake data using fundamental principles of energy physiology: 1. Derivation of cut-off limits to identify under-recording. Eur J Clin Nutr 1991;45(12):569581.

10. Black AE. The sensitivity and specificity of the Goldberg cut-off for El:BMR for identifying diet reports of poor validity. Eur J Clin Nutr 2000;54(5):395404.

11. Sundgot-Borgen J. Prevalence of eating disorders in elite female athletes. Int J Sport Nutr 1993;3(1):29-40.

12. Practice Committee of American Society for Reproductive Medicine. Current evaluation of amenorrhoea. Fertil Steril 2008:90(5 Suppl):S219-25.

13. Hoerr SL, Bokram R, Lugo B, Bivins T, Keast DR. Risk for disordered eating relates to both gender and ethnicity for college students. J Am Coll Nutr 2002;21(4):307-314. (http://www.jacn.org/content/21/4/307.full)
14. Kirk G, Singh K, Getz H. Risk of eating disorders among female college athletes and nonathletes. Journal of College Counselling 2001;4(Fall):122132.

15. Beals KA, Manore MM. Disorders of the female athlete triad among collegiate athletes. Int J Sport Nutr Exerc Metab 2002;12(3):281-293.

16. Torstveit MK, Rosenvinge JH, Sundgot-Borgen J. Prevalence of eating disorders and the predictive power of risk models in female elite athletes: a controlled study. Scand J Med Sci Sports 2008;18(1):108-118.

17. Reinking MF, Alexander LE. Prevalence of Disordered-Eating Behaviours in Undergraduate Female Collegiate Athletes and Nonathletes. J Athl Train 2005;40(1):47-51. (http://www.ncbi.nlm.nih.gov/pmc/articles/ PMC1088345/)

18. Torstveit MK, Sundgot-Borgen J. Participation in leanness sports but not training volume is associated with menstrual dysfunction: a national survey of 1276 elite athletes and controls. Br J Sports Med 2005;39(3):141-147. (http://bjsm.bmj.com/content/39/3/141.full)

19. Sundgot-Borgen J, Torstveit MK. The female football player, disordered eating, menstrual function and bone health. Br J Sports Med 2007;41(Suppl 1):i68-72. (http://bjsportmed.com/content/41/suppl 1/i68.full.html)

20. Beals KA, Hill AK. The prevalence of disordered eating, menstrual dysfunction, and low bone mineral density among US collegiate athletes. Int J Sport Nutr Exerc Metab 2006;16(1):1-23. 